\title{
NLS-RAR $\alpha$ modulates acute promyelocytic leukemia NB4 cell proliferation and differentiation via the PI3K/AKT pathway
}

\author{
HAO SONG ${ }^{1,2}$, LIU LI $^{2}$, LIANG ZHONG ${ }^{2}$, RONG YANG ${ }^{2}$, KAILING JIANG ${ }^{2}$, \\ XIAOQUN YANG ${ }^{2}$ and BEIZHONG LIU ${ }^{1,2}$ \\ ${ }^{1}$ Central Laboratory of Yong-Chuan Hospital, Chongqing Medical University, Chongqing 402160; \\ ${ }^{2}$ Department of Laboratory Medicine, The Key Laboratory of Diagnostics Medicine Designated by The Ministry of Education, \\ Chongqing Medical University, Chongqing 400016, P.R. China
}

Received September 29, 2015; Accepted October 18, 2016

DOI: $10.3892 / \mathrm{mmr} .2016 .5932$

\begin{abstract}
In patients with acute promyelocytic leukemia (APL), $\sim 98 \%$ express the promyelocytic leukemia (PML)-retinoic acid receptor $\alpha(\mathrm{RAR} \alpha)$ fusion protein. Previous studies have shown that, in primary leukemia cells of patients with APL, the cleavage of PML-RAR $\alpha$ by neutrophil elastase is important for its ability to initiate APL. This cleavage separates the nuclear localization signal (NLS) from PML, leading to the formation of a novel protein, NLS-RAR $\alpha$, although its underlying mechanism in APL remains to be fully elucidated. In the present study, the role of NLS-RAR $\alpha$ on the proliferation and differentiation of APL NB4 cells was investigated. Lentiviral vectors were constructed and transfected NLS-RAR $\alpha$ in NB4 cells, puromycin was used to select the stable transfected cell lines. Cell Counting Kit-8 and flow cytometry analysis revealed that the efficient overexpression of NLS-RAR $\alpha$ significantly promoted NB4 cell proliferation and inhibited all-trans retinoic acid-induced cell differentiation. Furthermore, the NLS-RAR $\alpha$ protein promoted a significant increase in AKT and glycogen synthase kinase $3 \beta$ (GSK-3 $\beta$ ) phosphorylation. The protein levels of phosphorylated (p) AKT and pGSK-3 $\beta$ were decreased following pretreatment with the phosphatidylinositol 3-kinase (PI3K) inhibitor, LY294002. These findings suggested that NLS-RAR $\alpha$ was an important molecule associated with the occurrence of APL via the PI3K-AKT signaling pathway, and indicated that the NLS-RAR $\alpha$ protein may be a novel target for the treatment of APL.
\end{abstract}

Correspondence to: Professor Beizhong Liu, Department of Laboratory Medicine, The Key Laboratory of Diagnostics Medicine Designated by The Ministry of Education, Chongqing Medical University, 1 Yixueyuan Road, Chongqing 400016, P.R. China

E-mail: liubeizhong@cqmu.edu.cn

Key words: nuclear localization signal-retinoic acid receptor $\alpha$, acute promyelocytic leukemia, NB4 cell, proliferation, differentiation, phosphatidylinositol 3-kinase/AKT

\section{Introduction}

Acute promyelocytic leukemia (APL) is a subtype of acute myeloid leukemia (AML), accounting for $10-15 \%$ of all cases of AML (1). APL is characterized by the selective expansion of immature hematopoietic precursors inhibited at the promyelocytic stage (1). Severe bleeding associated with disseminated intravascular coagulation and other complications can lead to early mortality rates in patients with APL (2). APL is characterized by the $\mathrm{t}(15 ; 17)$ translocation, which fuses the retinoic acid receptor $\alpha(\operatorname{RAR} \alpha)$ gene to the promyelocytic leukemia (PML) gene on chromosome 15, leading to the production of the PML/RAR $\alpha$ fusion protein. So far, the majority of investigations have focused on the PML/RAR $\alpha$ fusion protein as a whole, which interferes with the function of wild-type RAR $\alpha$ and PML, and suppresses the differentiation of promyelocytic cells $(3,4)$; however, the specific underlying mechanism remains to be fully elucidated. A study by Lane and Ley (5) found that the PML/RAR $\alpha$ fusion protein can be cleaved by neutrophil elastase (NE), and APL cells derived from human patients contain this PML-RAR $\alpha$ cleaving activity. This cleavage produces the novel protein, NLS-RAR $\alpha$. A previous study showed that the expression of PML/RAR $\alpha$ is associated with cellular toxicity, which is dependent on the expression of NE in early myeloid cells (6).

In addition to the PML/RAR $\alpha$ fusion gene, a number of other gene translocations have been reported in rare cases of APL. These fusion genes all have the same RAR $\alpha$ protein as a fusion partner, and all the resulting fusion proteins are fused with RAR $\alpha$ B through F domains (7). NLS-RAR $\alpha$ also has these domains (5), therefore, the present study hypothesized that NLS-RAR $\alpha$ may be important in initiating APL. Complete remission can be achieved in $90 \%$ of patients with APL treated with a combination of arsenic trioxide and all-trans retinoic acid (ATRA) (8). However, recurrence and resistance to ATRA treatment occurs in $20 \%$ of patients in complete remission. In addition, 10-30\% of patients with APL are resistant to ATRA $(9,10)$, and treatment with arsenic trioxide may cause cardiac toxicity, hepatic toxicity and neurotoxicity (11). Although the remission rate is higher, compared with those of other types of malignant tumor, the early mortality rate remains high (12). Therefore, it is important to further probe 
the molecular mechanisms underlying APL, and identify a novel target for its diagnosis and treatment.

In the present study, the role of NLS-RAR $\alpha$ in NB4 cells was examined using ATRA to induce differentiation. Furthermore, the potential molecular mechanisms modulated by NLS-RAR $\alpha$ in leukemogenesis were examined. The data revealed that the overexpression of NLS-RAR $\alpha$ promoted cell proliferation and inhibited differentiation via the PI3K/AKT signaling pathway. The results indicated that NLS-RAR $\alpha$ had a marked effect on APL pathogenesis and may be a novel target for the therapeutic treatment of APL.

\section{Materials and methods}

Cell lines and cell culture. Human acute promyelocytic leukemia NB4 and 293T cells were purchased from the Institute of Biochemistry and Cell Biology, Chinese Academy of Sciences (Shanghai, China). The cells were cultured in RPMI-1640 medium with 10\% fetal bovine serum (all purchased from Invitrogen Life Technologies; Thermo Fisher Scientific, Inc., Waltham, MA, USA) at $37^{\circ} \mathrm{C}$ in $5 \% \mathrm{CO}_{2}$.

Construction and packing of lentiviruses. The NLS-RAR $\alpha$ and RAR $\alpha$ genes were amplified by polymerase chain reaction (PCR) using pCMV-HA-NLS-RAR $\alpha$ and pCMV-Myc-RAR $\alpha$ plasmids as templates, respectively. The PCR product containing the sequence of the target gene was subcloned into the shuttle plasmid, LV5 (GenePharma Co., Ltd., Shanghai, China), between the NotI and BamHI restriction sites, whereas the LV5 plasmid with no target gene insert was selected as a negative control (NC). The LV5 shuttle plasmid contained the green fluorescent protein (GFP) gene. The four plasmids, comprising the packaging plasmids pGag/Pol, pRev, pVSV-G and the recombinant shuttle plasmid (GenePharma Co., Ltd., Shanghai, China), were transduced into $293 \mathrm{~T}$ cells $\left(5 \times 10^{6}\right)$ using Lipofectamine ${ }^{\mathrm{TM}} 2000$ (Invitrogen Life $^{2}$ Technologies; Thermo Fisher Scientific, Inc.) for $48 \mathrm{~h}$. The viral supernatant was later centrifuged at $6,000 \times \mathrm{g}$ for $2 \mathrm{~h}$ at $4^{\circ} \mathrm{C}$, then concentrated by $0.45 \mu \mathrm{m}$ filter and the titer determined.

Generation of stably transfected cell lines. NB4 cells were subcultured into a 24-well culture plate at a density of $\sim 5 \times 10^{4}$ cells/well. Each well was supplemented with $5 \mu \mathrm{g}$ polybrene (Sigma-Aldrich; Merck Millipore, Darmstadt, Germany), and the cells were infected with the LV5-NLS-RAR $\alpha$ lentivirus (LV-NLS-RAR $\alpha$ group), LV5-RAR $\alpha$ lentivirus (LV-RAR $\alpha$ group) or negative control LV5 lentivirus (LV-NC group), respectively, at a multiplicity of infection of 150 . After $24 \mathrm{~h}$ incubated at $37^{\circ} \mathrm{C}$ in $5 \% \mathrm{CO}_{2}$, the complete medium was replaced without polybrene. A fluorescence microscope was used to observe the expression of GFP. At $72 \mathrm{~h}$ post-infection, stably transfected cell lines were selected using puromycin (Sigma-Aldrich; Merck Millipore) at a dose of $1 \mu \mathrm{g} / \mathrm{ml}$ for 7 days to establish the NLS-RAR $\alpha$, RAR $\alpha$ and NC cell lines. The NB4 cell line was selected as a blank control (control group).

Cell viability assay. The viabilities of the NB4 cells infected with the lentiviruses were detected using a Cell Counting Kit-8 (CCK-8) assay (7SeaPharmTech, Shanghai, China) within 5 days at different incubation time points $(0,24,48,72$ and $96 \mathrm{~h}$ ). The absorbance was measured at $450 \mathrm{~nm}$ using a microplate reader.

Cell cycle assay. To examine the cell cycle, $1 \times 10^{6}$ cells in each group were washed twice with PBS and were fixed with pre-cold $75 \%$ ethanol for $2 \mathrm{~h}$ at $4^{\circ} \mathrm{C}$. Cell cycle was examined using flow cytometry (Beckman Coulter, Brea, CA, USA) at $488 \mathrm{~nm}$. Data were analyzed using the Multicycle DNA content and cell analysis software program AV (Phoenix Flow System, Inc., San Diego, CA, USA)

Cell differentiation assay. For detection of the cell differentiation antigen, CD11b, ATRA (Sigma-Aldrich; Merck Millipore) was used to induce cell differentiation at a concentration of $1 \mathrm{nM}$ for 3 days. The cells ( $1 \times 10^{6} /$ group) were washed twice with PBS and incubated with phycoerythrin (PE)-conjugated CD11b antibody (cat. no. 12-0113-42; eBioscience, Inc., San Diego, CA, USA) at $4^{\circ} \mathrm{C}$ for $30 \mathrm{~min}$ in the dark. The cells were then analyzed using flow cytometry (BD FACS Vantage; BD Biosciences, San Jose, CA, USA) and CellQuest Pro software version 5.1 (BD Pharmingen, San Diego, CA, USA).

Western blot analysis. The cells were lysed on ice in RIPA lysis buffer (Beyotime Institute of Biotechnology, Jiangsu, China) with protease inhibitor (PMSF) and phosphatase inhibitors (NaF and $\mathrm{Na}_{3} \mathrm{VO}_{4}$; Roche Diagnostics, Basel, Switzerland). A BCA protein assay kit (Beyotime Institute of Biotechnology) was used to measure protein concentration. A loading buffer (5X) was added to all protein solutions, which were then boiled for $5 \mathrm{~min}$. Equal quantities $(50 \mu \mathrm{m})$ of proteins were separated by $10 \%$ SDS-PAGE and then transferred onto PVDF membranes (EMD Millipore, Billerica, MA, USA). The PVDF membranes were then blocked with $0.1 \%$ Tween-20 in TBS containing 5\% nonfat dry milk for $2 \mathrm{~h}$ at room temperature. The membranes were incubated with primary antibodies against AKT (cat. no. ab32505; 1:1,000; Abcam, Cambridge, UK), glycogen synthase kinase $3 \beta$ (GSK3 $\beta$; cat. no. 12456), c-myc (cat. no. 5605), cyclin D1 (cat. no. 2978; 1:1,000; Cell Signaling Technology, Inc., Danvers, MA, USA), and $\beta$-actin (cat. no. BM0627; 1:1,000, Boster Biological Technology Ltd., Wuhan, China) overnight at $4^{\circ} \mathrm{C}$. The membranes were washed three times with TBST and incubated with horseradish peroxidase (HRP)-conjugated secondary antibodies (cat. nos. ZDR-5307 and ZDR-5306; ZSGB-Bio, Beijing, China) for $1 \mathrm{~h}$ at room temperature. Protein bands were visualized by incubating the membranes in chemiluminescent HRP substrate were and analyzed using Adobe Photoshop 12.0 software (Adobe Systems, Inc., San Jose, CA, USA).

Statistical analysis. SPSS 17.0 software (SPSS, Inc., Chicago, IL, USA) was used for statistical analysis. The results are represented as the mean \pm standard deviation $(n \geq 3)$ and were compared using one-way analysis of variance. $\mathrm{P}<0.05$ was considered to indicate a statistically significant difference.

\section{Results}

NB4 cell transduction induces the expression of NLS-RAR $\alpha$. The fluorescence of the NB4 cells showed that $\sim 90 \%$ of the cells 
A

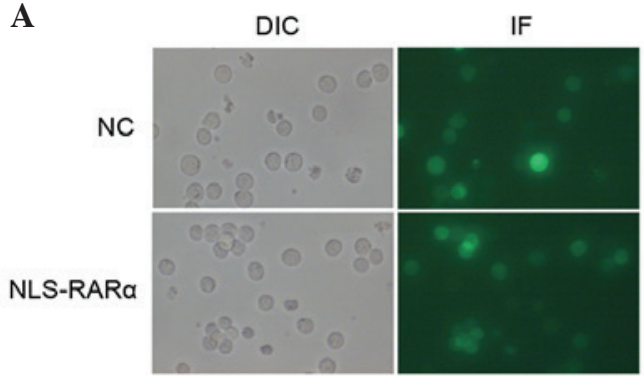

B

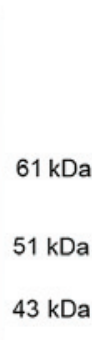

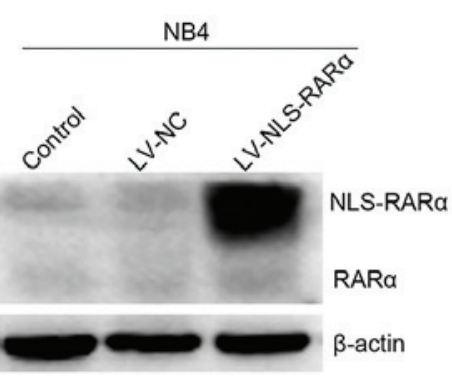

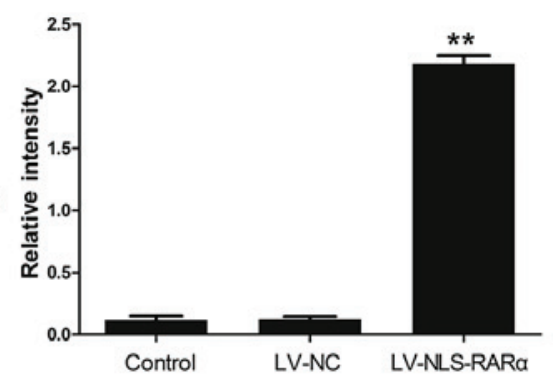

Figure 1. NB4 cell transduction induces the expression of NLS-RAR $\alpha$. (A) Expression of green fluorescent protein in each group. Magnification, x100. (B) NLS-RAR $\alpha$ gene was overexpressed in the LV-NLS-RAR $\alpha$ group. Data are represented as the mean \pm standard deviation. ** $<0.01$ LV-NLS-RAR $\alpha$ group, vs. control or LV-NC group. NLS-RAR $\alpha$, nuclear localization signal-retinoic acid receptor $\alpha$; NC, negative control; LV, lentivirus; DIC, differential interference contrast; IF, immunofluorescence.

A

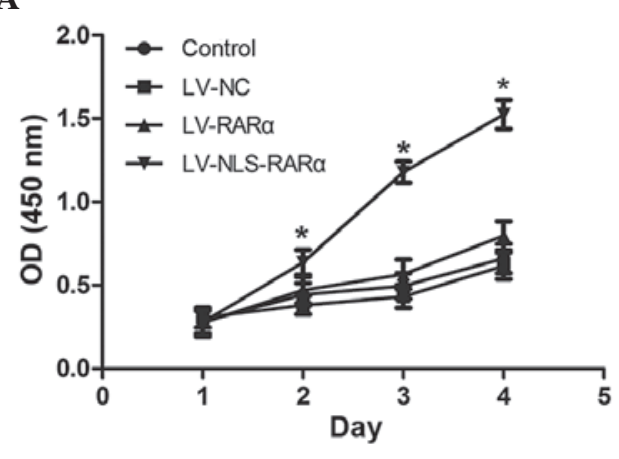

C

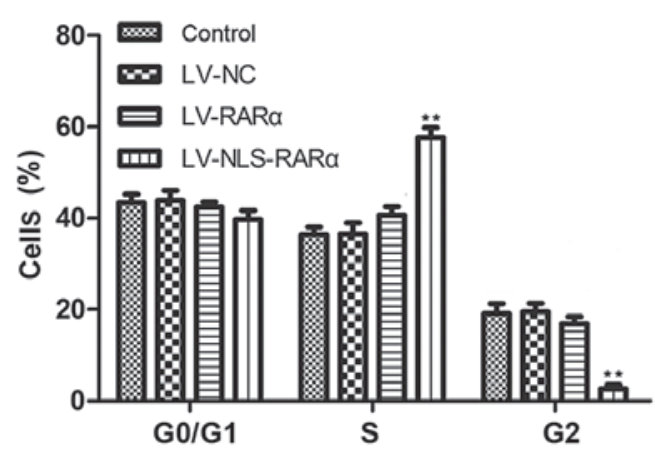

B
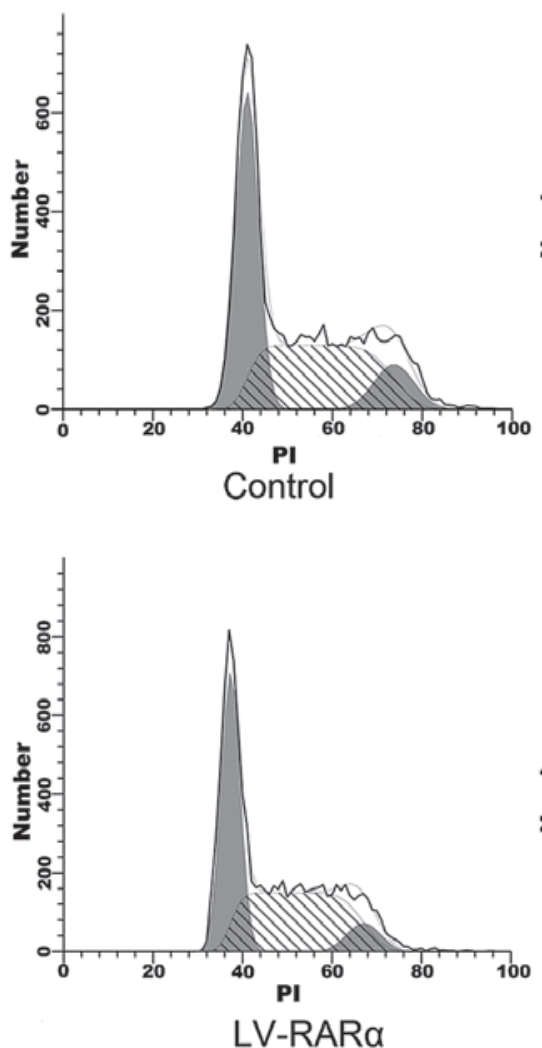
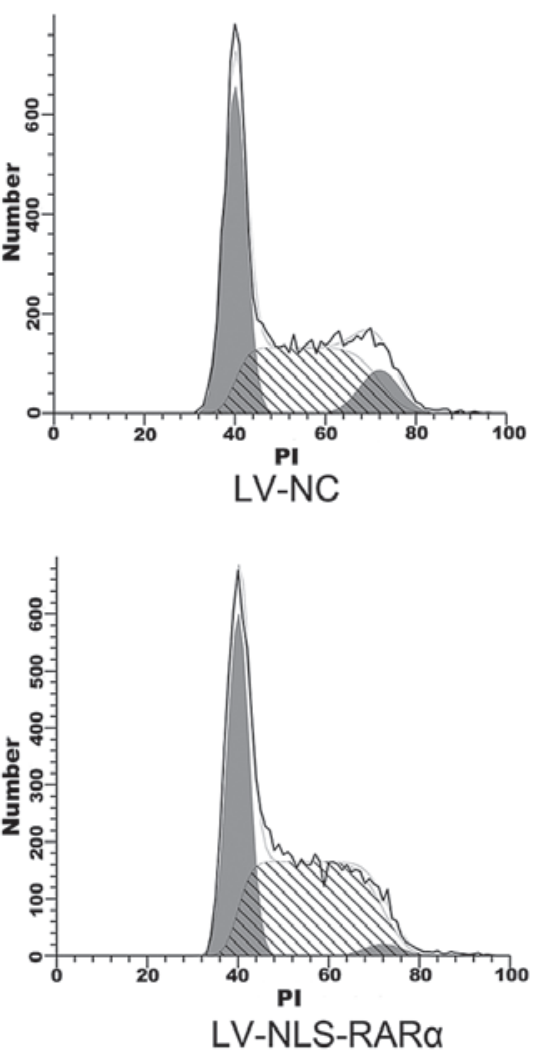

Figure 2. NLS-RAR $\alpha$ promotes the proliferation of NB4 cells. (A) Cell growth promotion by NLS-RAR $\alpha$. Each group was repeatedly detected in five wells to exam absorbance. The absorbance was detected using a Cell Counting Kit-8 assay for 4 days. "P<0.05 LV-NLS-RAR $\alpha$ group, vs. control, LV-NC or LV-RAR $\alpha$ group. (B and C) Cell cycle analysis showed that the overexpression of NLS-RAR $\alpha$ increased the number of NB4 cells in the S-phase and decreased the number of cells in the G2-phase. ${ }^{* *} \mathrm{P}<0.01 \mathrm{LV}-\mathrm{NLS}-\mathrm{RAR} \alpha$ group, vs. control, LV-NC or LV-RAR $\alpha$ group. Data are presented as the mean \pm standard deviation. NLS-RAR $\alpha$, nuclear localization signal-retinoic acid receptor $\alpha$; NC, negative control; LV, lentivirus; OD, optical density; PI. propidium iodide.

were transduced by the lentiviral vectors (Fig. 1A). To establish a stable NLS-RAR $\alpha$ cell line, puromycin was used to screen the infected cells. Western blot analysis, with $\beta$-actin as an internal reference, showed that the NLS-RAR $\alpha / \beta$-actin intensity ratio was $2.18 \pm 0.11$, which indicated that the NLS-RAR $\alpha$ gene was efficiently expressed in the LV-NLS-RAR group (Fig. 1B).

Overexpression of NLS-RAR $\alpha$ promotes the proliferation of NB4 cells. The proliferative abilities of the cells were examined using a CCK-8 assay. As shown in Fig. 2A, the overexpression of the NLS-RAR $\alpha$ protein promoted the proliferation of the
NB4 APL cells $\left({ }^{*} \mathrm{P}<0.05\right)$. No statistically significant difference were found between the blank control, negative control and LV-RAR $\alpha$ groups. Therefore, the overexpression of NLS-RAR $\alpha$ specifically induced the proliferation of the APL cells.

To determine whether the NLS-RAR $\alpha$ protein affected the cell cycle of the NB4 cells, flow cytometry was used to assess the cell cycle distribution (Fig. 2B). The results showed that the overexpression of NLS-RAR $\alpha$ led to a significant increase $(57.63 \pm 1.17 \%)$ in the number of cells in the S-phase and a decrease $(2.63 \pm 0.91 \%)$ in the G2-phase of the cell cycle suggesting that NLS-RAR $\alpha$ protein promoted cell proliferation by enhancing cell cycle progression (Fig. 2C). 

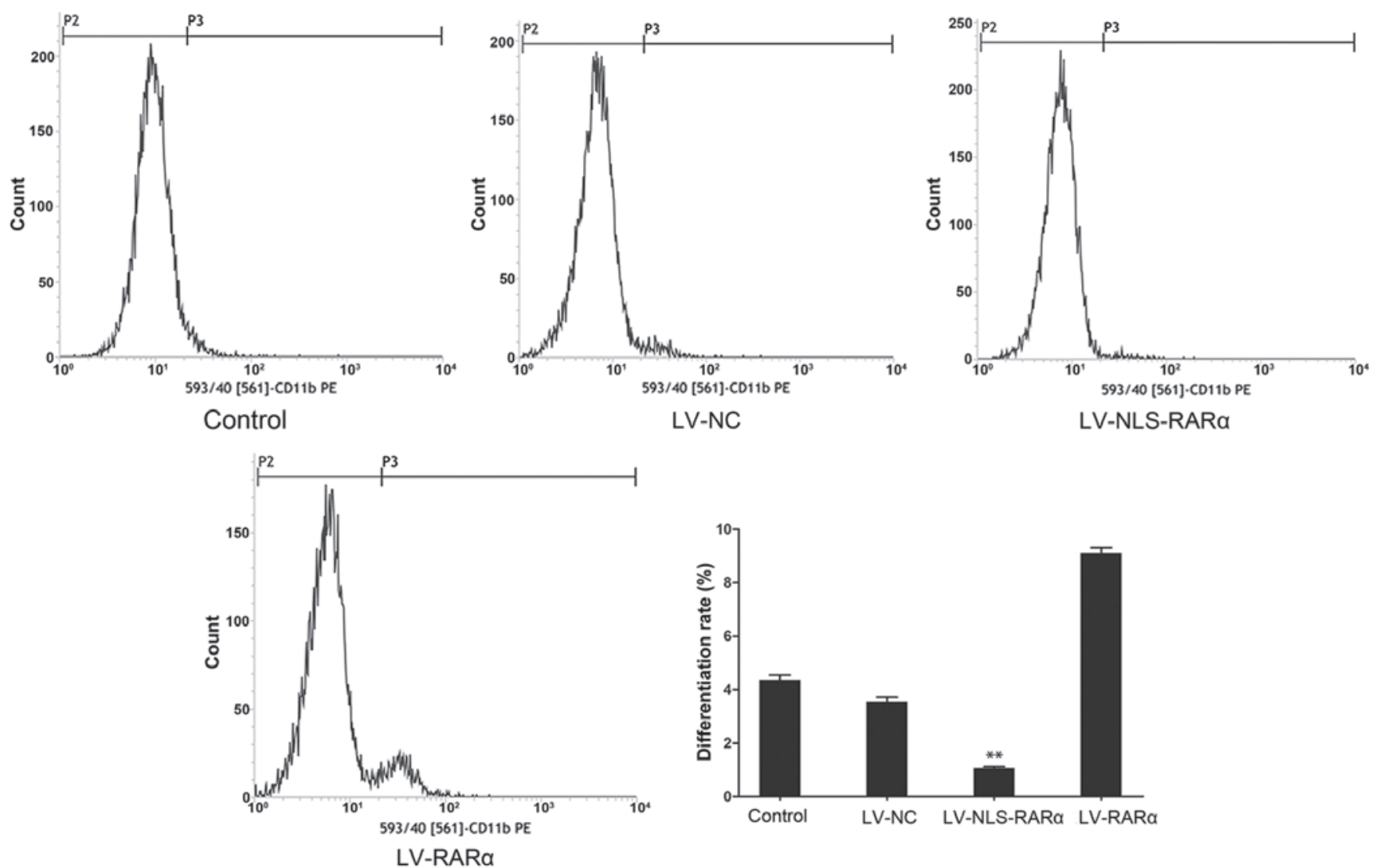

Figure 3. NLS-RAR $\alpha$ inhibits the differentiation of NB4 cells. The differentiation rates of each group were detected using flow cytometry. All-trans retinoic acid was used to induce cell differentiation at a concentration of $1 \mathrm{nM}$. The differentiation rate of cells in the LV-NLS-RAR $\alpha$ group decreased significantly. ${ }^{* *} \mathrm{P}<0.01$ LV-NLS-RAR $\alpha$ group, vs. control, LV-NC or LV-RAR $\alpha$ group. Data are represented as the mean \pm standard deviation. NLS-RAR $\alpha$, nuclear localization signal-retinoic acid receptor $\alpha$; NC, negative control; LV, lentivirus; PE, phycoerythrin.

Overexpression of NLS-RAR $\alpha$ inhibits the differentiation of NB4 cells. Flow cytometric analysis for the determination of NB4 cell differentiation was based on the detection of PE-conjugated CD11b antibody fluorescence. The percentage of total differentiated cells was significantly decreased $(0.98 \pm 0.06 \%)$ in the LV-NLS-RAR $\alpha$ group, compared with the blank control $(4.56 \pm 0.15 \%)$, negative control $(3.48 \pm 0.11 \%)$ and LV-RAR $\alpha$ groups $(9.49 \pm 0.19 \%)$, as shown in Fig. 3. The analysis showed that the NLS-RAR $\alpha$ protein inhibited the ATRA-induced cell differentiation.

Overexpression of NLS-RAR $\alpha$ activates the PI3K/AKT pathway. To further define the molecular mechanisms modulated by NLS-RAR $\alpha$ in the proliferation and differentiation of NB4 cells, the protein expression of proliferation- and differentiation-associated genes in the NLS-RAR $\alpha$-overexpressing cells were detected. It was found that the protein expression of c-myc and the phosphorylation of AKT (Ser473) and GSK3 $\beta$ (Ser9) increased, although no difference was found in the protein expression of cyclin D1. The cells transduced with LV-NLS-RAR $\alpha$, which were pretreated with $20 \mu \mathrm{M}$ of the PI3K inhibitor, LY294002, showed that it significantly inhibited the phosphorylation of AKT (Ser473) and its downstream target, GSK3 $\beta$ (Ser9). These results indicated that the NLS-RAR $\alpha$ protein exerted proliferative and anti-differentiation effects in the APL cells, at least partly through the PI3K/AKT pathway (Fig. 4).

\section{Discussion}

Previous studies have shown that NE is important for the ability of PML-RAR $\alpha$ to initiate APL in transgenic mice models of this disease. Primary mouse and human APL cells also exhibit NE-dependent PML-RAR $\alpha$ cleaving activity (5). In the present study, to further investigate the functional role of NLS-RAR $\alpha$, the overexpression of NLS-RAR $\alpha$ was induced in APL NB4 cells through the process of lentiviral transfection. The results showed that NLS-RAR $\alpha$ promoted cell proliferation, and caused a significant increase in S-phase cells and decrease in G2-phase cells, thus promoting cell cycle progression. Human wild-type RAR $\alpha$ is a ligand-dependent transcription factor, which requires combination with retinoid $X$ receptor $\alpha(R X R \alpha)$ to respond to ATRA. The RAR $\alpha / R X R \alpha$ heterodimer binds to specific DNA sequences of the retinoic acid response element in the promoter regions of target genes and regulates the transcription of these genes (13). RAR $\alpha$ target genes, including p21, RAR $\beta$, transglutaminase II and homeobox genes, are important in the regulation of cell proliferation and differentiation (4). PML-RAR $\alpha$ can compete with wild-type RAR $\alpha$ for RXR $\alpha$ and interfere in the regulation of transcription (14). The function of NLS-RAR $\alpha$ may be similar to PML-RAR $\alpha$, which interferes with RAR $\alpha$.

Our previous experiments showed that NLS-RAR $\alpha$, which has PML nuclear localization signal, shows increased distribution in the nucleus, compared with wild-type RAR $\alpha$ (15). 

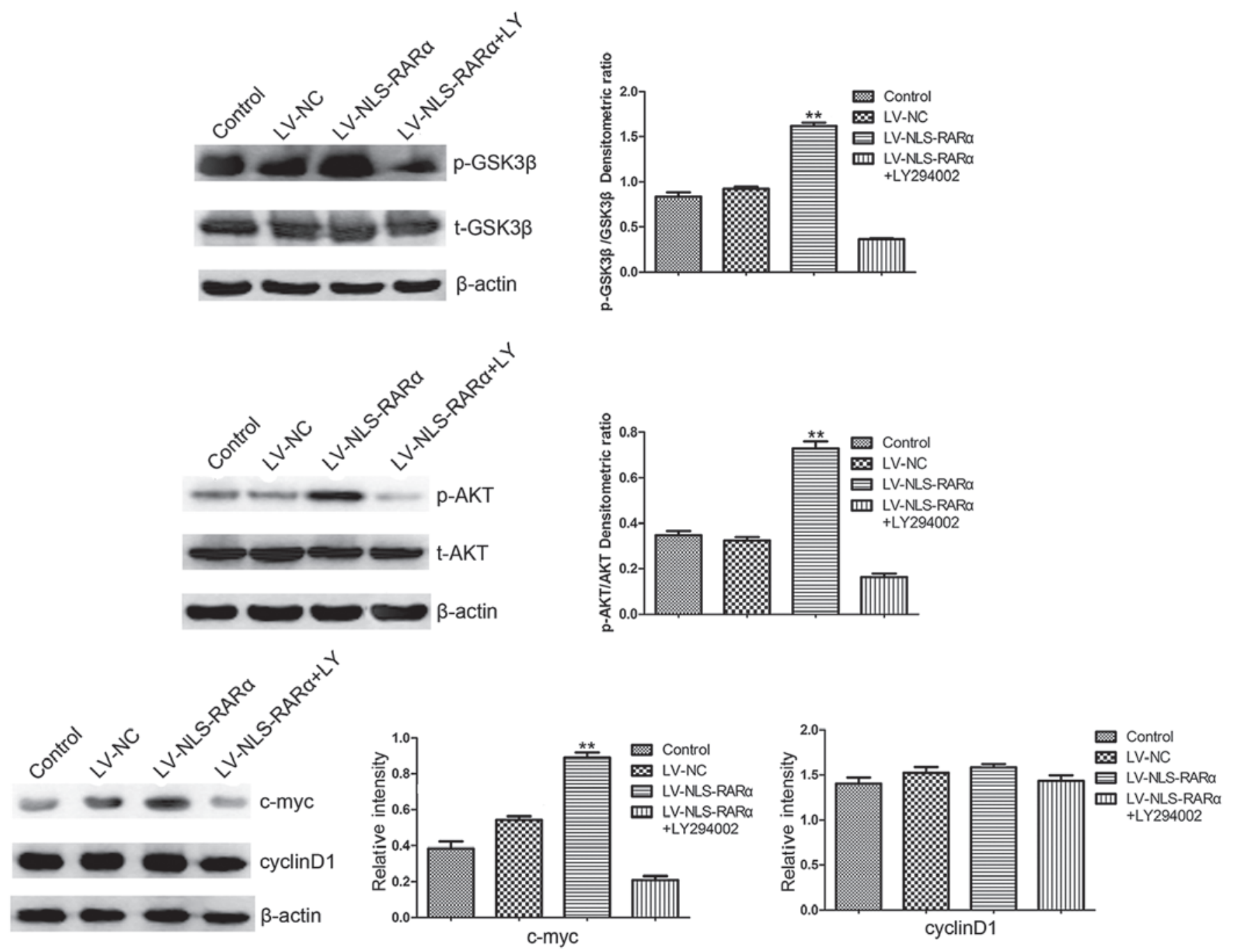

Figure 4. Western blot analysis detection of the expression of p-AKT and p-GSK3 $\beta$, c-myc and cyclin D1. Each group of cells were lysed and analyzed using western blot analysis. The LV-NLS-RAR $\alpha$ group was pretreated with $20 \mu \mathrm{M}$ PI3K inhibitor (LY294002) for $24 \mathrm{~h}$. Date are presented as the mean \pm standard deviation ( $\mathrm{n}=3$ ) and analyzed using one-way analysis of variance. $\mathrm{p}-\mathrm{AKT}$, p-GSK3 $\beta$, and c-myc: ${ }^{* *} \mathrm{P}<0.01, \mathrm{LV}-\mathrm{NLS}-\mathrm{RAR} \alpha$ group, vs. control, LV-NC or LV-NLS-RAR $\alpha+L Y 294002$ group. Cyclin D1: P>0.05 LV-NLS-RAR $\alpha$ group, vs. control, LV-NC or LV-NLS-RAR $\alpha+L Y 294002$ group. NLS-RAR $\alpha$, nuclear localization signal-retinoic acid receptor $\alpha$; NC, negative control; LV, lentivirus; p-, phosphorylated.

Several studies have found that alterations in protein localization can affect cell function (16,17). The occurrence of tumors may be associated with the abnormal localization of proteins; therefore, it was hypothesized that alterations in protein location were also implicated in the pathogenesis of APL. The CD11b myeloid differentiation antigen is a marker of mature myeloid cell differentiation (18). The results of the present study confirmed that, following ATRA treatment to induce cell differentiation, the expression of CD11b was reduced significantly in the LV-NLS-RAR $\alpha$ group, compared with that in the control group, demonstrating that the overexpression of NLS-RAR $\alpha$ inhibited cell maturation.

To determine the effects of NLS-RAR $\alpha$ on proliferation and differentiation, the present study focused on the AKT-GSK3 $\beta$-c-myc-cyclin D1 pathway. Previous studies have shown that AKT is activated abnormally in several types of cancer, including leukemia (19-21). The PI3K/AKT pathway coordinately regulates diverse cellular programs, including proliferation, differentiation and apoptosis. In the present study, it was demonstrated that the over-expression of
NLS-RAR $\alpha$ increased the AKT serine/threonine phosphorylation and caused upregulation of the downstream proteins, pGSK and c-myc. As an important oncogene, constitutively expressing a high level of c-myc leads to a reduced growth factor requirement, shorter duration in the $\mathrm{G} 1$ phase and an increased growth rate. Furthermore, c-myc can inhibit differentiation by preventing cells from leaving the cell cycle (22). AKT phosphorylates numerous substrates to modify their function (19), including GSK-3 $\beta$ associated with the regulation of cell proliferation and differentiation (23). Additionally, GSK-3 $\beta$ has been shown to negatively regulate the stability and expression of the cell-cycle regulator, cyclin D1 (24). Cyclin D1 is an important downstream of AKT, which can promote G1-S progression associated with cell growth (25). Previous studies have showed that PI3K/AKT activity is also critical in cellular differentiation processes $(26,27)$; it negatively regulates granulocyte differentiation. ATRA, through deactivation of the PI3K/AKT signaling pathways, induces the differentiation of APL cells (28). Previously, Srinivas et al (29) demonstrated that RAR $\alpha$ interacts with AKT through the DNA 
binding domain, which is also present in NLS-RAR $\alpha$. Our previous study showed that NLS-RAR $\alpha$ interacts with AKT, which may be one of the AKT pathway-activating factors (30). Thus, it is essential to further determine whether their direct interaction activates the AKT pathway.

In conclusion, the data obtained in the present study demonstrated that the overexpression of NLS-RAR $\alpha$ promoted the proliferation of APL cells and inhibited their differentiation via the PI3K/AKT signaling pathway. These results provide novel insight into the mechanisms of leukemogenesis. Future investigations aim to specifically target NLS-RAR $\alpha$ as a therapeutic option for diagnosis and treatment response.

\section{Acknowledgements}

This study was supported by the National Natural Science Foundation of China (grant no. 81171658) and the Natural Science Foundation Project of CQ CSTC (grant no. 2011BA5037).

\section{References}

1. Warrell RP Jr, de Thé H, Wang ZY and Degos L: Acute promyelocytic leukemia. N Engl J Med 329: 177-189, 1993.

2. Lo-Coco F and Cicconi L: History of acute promyelocytic leukemia: A tale of endless revolution. Mediterr J Hematol Infect Dis 3: e2011067, 2011.

3. Grignani F, Ferrucci PF, Testa U, Talamo G, Fagioli M, Alcalay M, Mencarelli A, Grignani F, Peschle C, Nicoletti I, et al: The acute promyelocytic leukemia-specific PML-RAR alpha fusion protein inhibits differentiation and promotes survival of myeloid precursor cells. Cell 74: 423-431, 1993.

4. Laurenzana A, Pettersson F and Miller WH Jr: Role of PML-RAR $\alpha$ in the pathogenesis of APL. Drug Discov Today Dis Mech 3: 499-505, 2006.

5. Lane AA and Ley TJ: Neutrophil elastase cleaves PML-RARalpha and is important for the development of acute promyelocytic leukemia in mice. Cell 115: 305-318, 2003.

6. Lane AA and Ley TJ: Neutrophil elastase is important for PML-retinoic acid receptor alpha activities in early myeloid cells. Mol Cell Biol 25: 23-33, 2005.

7. di Masi A, Leboffe L, De Marinis E, Pagano F, Cicconi L, Rochette-Egly C, Lo-Coco F, Ascenzi P and Nervi C: Retinoic acid receptors: From molecular mechanisms to cancer therapy. Mol Aspects Med 41: 1-115, 2015.

8. Wang ZY and Chen Z: Acute promyelocytic leukemia: From highly fatal to highly curable. Blood 111: 2505-2515, 2008.

9. Huang ME, Ye YC, Chen SR, Chai JR, Lu JX, Zhao L, Gu LJ and Wang ZY: Use of all-trans retinoic acid in the treatment of acute promyelocytic leukemia. Blood 72: 567-572, 1988.

10. Breccia M, Cicconi L and Lo-Coco F: ATRA+ ATO: Has a new standard of care been established in low-risk acute promyelocytic leukaemia? Curr Opin Hematol 21: 95-101, 2014.

11. Iland HJ and Seymour JF: Role of arsenic trioxide in acute promyelocytic leukemia. Curr Treat Options Oncol 14: 170-184, 2013.

12. Park JH, Qiao B, Panageas KS, Schymura MJ, Jurcic JG, Rosenblat TL, Altman JK, Douer D, Rowe JM and Tallman MS: Early death rate in acute promyelocytic leukemia remains high despite all-trans retinoic acid. Blood 118: 1248-1254, 2011.
13. De Braekeleer E, Douet-Guilbert N and De Braekeleer M: RARA fusion genes in acute promyelocytic leukemia: A review. Expert Rev Hematol 7: 347-357, 2014.

14. Soprano DR, Qin P and Soprano KJ: Retinoic acid receptors and cancers. Annu Rev Nutr 24: 201-221, 2004.

15. Wang H, Zhong L, Jiang KL, Zhu XY, Ma PP, Yang XQ and Liu BZ: Location verification of NLS-RAR $\alpha$ protein in infected NB4 cell line with adenovirus Ad-NE. Chin J Cell Biol 36: 331-337, 2014. (In Chinese).

16. Marshall KS, Cohen MJ, Fonseca GJ, Todorovic B, King CR, Yousef AF, Zhang Z and Mymryk JS: Identification and characterization of multiple conserved nuclear localization signals within adenovirus E1A. Virology 454-455: 206-214, 2014.

17. Sun Z, Wu T, Zhao F, Lau A, Birch CM and Zhang DD: KPNA6 (Importin \{alpha\}7)-mediated nuclear import of Keap1 represses the Nrf2-dependent antioxidant response. Mol Cell Biol 31: 1800-1811, 2011.

18. Rizzatti EG, Garcia AB, Portieres FL, Silva DE, Martins SL and Falcão RP: Expression of CD117 and CD11b in bone marrow can differentiate acute promyelocytic leukemia from recovering benign myeloid proliferation. Am J Clin Pathol 118: 31-37, 2002.

19. Vivanco I and Sawyers CL: The phosphatidylinositol 3-kinase-AKT pathway in human cancer. Nat Rev Cancer 2: 489-501, 2002.

20. Cumberbatch M, Tang X, Beran G, Eckersley S, Wang X, Ellston RP, Dearden S, Cosulich S, Smith PD, Behrens C, et al: Identification of a subset of human non-small cell lung cancer patients with high PI3K $\beta$ and low PTEN expression, more prevalent in squamous cell carcinoma. Clin Cancer Res 20: 595-603, 2014.

21. Xie X, Tang B, Zhou J, Gao Q and Zhang P: Inhibition of the PI3K/Akt pathway increases the chemosensitivity of gastric cancer to vincristine. Oncol Rep 30: 773-782, 2013.

22. Henriksson M and Lüscher B: Proteins of the Myc network: Essential regulators of cell growth and differentiation. Adv Cancer Res 68: 109-182, 1996.

23. Wray J, Kalkan T, Gomez-Lopez S, Eckardt D, Cook A, Kemler R and Smith A: Inhibition of glycogen synthase kinase-3 alleviates Tcf 3 repression of the pluripotency network and increases embryonic stem cell resistance to differentiation. Nat Cell Biol 13: 838-845, 2011.

24. Ougolkov AV and Billadeau DD: Targeting GSK-3: A promising approach for cancer therapy? Future Oncol 2: 91-100, 2006.

25. Diehl JA, Cheng M, Roussel MF and Sherr CJ: Glycogen synthase kinase-3beta regulates cyclin D1 proteolysis and subcellular localization. Gene Dev 12: 3499-3511, 1998.

26. Qiao J, Paul P, Lee S, Qiao L, Josifi E, Tiao JR and Chung DH: PI3K/AKT and ERK regulate retinoic acid-induced neuroblastoma cellular differentiation. Biochem Biophs Res Commun 424: 421-426, 2012.

27. Kim JM, Yoon M, Kim J, Kim SS, Kang I, Ha J and Kim SS: Phosphatidylinositol 3-kinase regulates differentiation of $\mathrm{H} 9 \mathrm{c} 2$ cardiomyoblasts mainly through the protein kinase B/Akt-independent pathway. Arch Biochem Biophys 367: 67-73, 1999.

28. Ozpolat B, Akar U, Steiner M, Zorrilla-Calancha I, Tirado-Gomez M, Colburn N, Danilenko M, Kornblau S and Berestein GL: Programmed cell death-4 tumor suppressor protein contributes to retinoic acid-induced terminal granulocytic differentiation of human myeloid leukemia cells. Mol Cancer Res 5: 95-108, 2007.

29. Srinivas H, Xia D, Moore NL, Uray IP, Kim H, Ma L, Weigel NL, Brown PH and Kurie JM: Akt phosphorylates and suppresses the transactivation of retinoic acid receptor alpha. Biochem J 395: 653-662, 2006.

30. Jiang K, Yang X, Ma P, Wang H, Zhu X, Liu B and Zhong L: NLS-RAR $\alpha$ : A novel transcriptional factor. Oncol Lett (In press). 